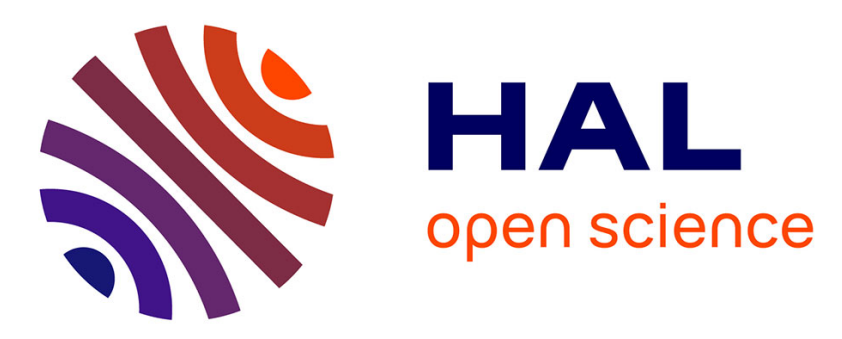

\title{
Jetfire lab: Jetfire at reduced scale
}

Johan Sarazin, Elsa Franchini, Virginie Dréan, Roman Chiva, Serge Bourbigot

\section{To cite this version:}

Johan Sarazin, Elsa Franchini, Virginie Dréan, Roman Chiva, Serge Bourbigot. Jetfire lab: Jetfire at reduced scale. Journal of Fire Sciences, 2021, Journal of Fire Sciences, pp.073490412110371. 10.1177/07349041211037192 . hal-03352830

\section{HAL Id: hal-03352830 \\ https://hal.univ-lille.fr/hal-03352830}

Submitted on 23 Sep 2021

HAL is a multi-disciplinary open access archive for the deposit and dissemination of scientific research documents, whether they are published or not. The documents may come from teaching and research institutions in France or abroad, or from public or private research centers.
L'archive ouverte pluridisciplinaire HAL, est destinée au dépôt et à la diffusion de documents scientifiques de niveau recherche, publiés ou non, émanant des établissements d'enseignement et de recherche français ou étrangers, des laboratoires publics ou privés. 


\title{
Page Proof Instructions and Queries
}

\author{
Journal Title: \\ JFS \\ Article Number: \\ 1037192
}

Thank you for choosing to publish with us. This is your final opportunity to ensure your article will be accurate at publication. Please review your proof carefully and respond to the queries using the circled tools in the image below, which are available in Adobe Reader DC* by clicking Tools from the top menu, then clicking Comment.

Please use only the tools circled in the image, as edits via other tools/methods can be lost during file conversion. For comments, questions, or formatting requests, please use $\mathrm{T}$. Please do not use comment bubbles/sticky notes $\ominus$.

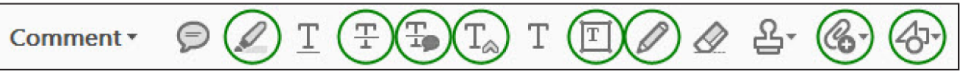

*If you do not see these tools, please ensure you have opened this file with Adobe Reader DC, available for free at get.adobe.com/reader or by going to Help > Check for Updates within other versions of Reader. For more detailed instructions, please see us.sagepub.com/ReaderXProofs.

\begin{tabular}{|c|c|}
\hline Sl. No. & Query \\
\hline & $\begin{array}{l}\text { Please note that we cannot add/amend orcid ids for any article at the } \\
\text { proof stage. following orcid's guidelines, the publisher can include only } \\
\text { orcid ids that the authors have specifically validated for each manuscript } \\
\text { prior to official acceptance for publication. }\end{array}$ \\
\hline & $\begin{array}{l}\text { Please confirm that all author information, including names, affiliations, } \\
\text { sequence, and contact details, is correct. }\end{array}$ \\
\hline & $\begin{array}{l}\text { Please review the entire document for typographical errors, mathemati- } \\
\text { cal errors, and any other necessary corrections; check headings, tables, } \\
\text { and figures. }\end{array}$ \\
\hline & $\begin{array}{l}\text { Please ensure that you have obtained and enclosed all necessary permis- } \\
\text { sions for the reproduction of artworks (e.g. illustrations, photographs, } \\
\text { charts, maps, other visual material, etc.) not owned by yourself. please } \\
\text { refer to your publishing agreement for further information. }\end{array}$ \\
\hline & $\begin{array}{l}\text { Please note that this proof represents your final opportunity to review } \\
\text { your article prior to publication, so please do send all of your changes } \\
\text { now. }\end{array}$ \\
\hline & $\begin{array}{l}\text { Please confirm that the funding and conflict of interest statements are } \\
\text { accurate. }\end{array}$ \\
\hline 1 & $\begin{array}{l}\text { Please check whether the edits made to the sentence 'Jetfire at such } \\
\text { reduced scale ...' are correct. }\end{array}$ \\
\hline 2 & $\begin{array}{l}\text { Please check whether the edits made to the sentence 'The two boxes were } \\
\text { designed ...' are correct. }\end{array}$ \\
\hline 3 & $\begin{array}{l}\text { Please check whether the edits made to the sentence 'Junction between } \\
\text { panels have ...' are correct. }\end{array}$ \\
\hline 4 & $\begin{array}{l}\text { Please check whether the edits made to the sentence 'The junction area } \\
\text { between the ...' are correct. }\end{array}$ \\
\hline 5 & $\begin{array}{l}\text { Please check whether the edits made to the sentence 'Even though the } \\
\text { erosion ...' are correct. }\end{array}$ \\
\hline
\end{tabular}


Please check whether the edits made to the sentence 'In addition, the heat dissipation ...' are correct. Please provide a 2-3 sentence biography for each of the authors. Please provide publisher details for Reference 1. 


\section{Jetfire lab: Jetfire at reduced scale}

\section{Johan Sarazin', Elsa Franchini' ${ }^{2}$, Virginie Dréan ${ }^{3}$, Roman Chiva ${ }^{3}$, Serge Bourbigot ${ }^{1,4}$}

Date received: 3 I May 202 I; accepted: I4 July 202 I
Journal of Fire Sciences

(C) The Author(s) 2021

Article reuse guidelines: sagepub.com/journals-permissions DOI: $10.1177 / 07349041211037192$ journals.sagepub.com/home/jfs

@SAGE

\begin{abstract}
This article addresses the development of a bench-scale test (jetfire lab) mimicking the fire exposure of the large-scale jetfire facility. An experimental approach was addressed to develop direct correlation and to validate the similitude between bench-scale test and large-scale jetfire. Comparisons were made by testing Zaltex passive fire protection material in the form of panels. Novel setups were designed to make the jetfire lab able to measure time/temperature curves similar to those obtained at a large scale. The assembly of the tested samples was also investigated. An experimental protocol was elaborated to consider the junction between parts of the sample at the reduced scale. Direct correlation was found between the large and the bench scale and it was evidenced that jetfire lab can be used for preliminary study and development of new thermal barriers for fire protection.
\end{abstract}

\title{
Keywords
}

Jetfire, bench scale, passive fire protection, similitude

\section{Introduction}

The history of fire regulation is often linked to a catastrophic accident. The large fire happening in the offshore platform Piper Alpha (6 July 1988) led to a new test procedure after understanding and analyzing the accident. ${ }^{1,2}$ Large-scale facility and test protocol were then established to evaluate the fire resistance of passive fire protection (PFP) systems against

\footnotetext{
'University of Lille, CNRS, INRAE, Centrale Lille, UMR 8207-UMET-Unité Matériaux Et Transformations, Lille, France ${ }^{2}$ Hutchinson, Precision Sealing Division, Chalette sur Loing, France

${ }^{3}$ Efectis France, route de l'Orme des Merisiers, Saint Aubin, France

${ }^{4}$ Institut Universitaire de France (IUF), Paris, France
}

\section{Corresponding author:}

Serge Bourbigot, University of Lille, CNRS, INRAE, Centrale Lille, UMR 8207-UMET-Unité Matériaux Et Transformations, 59000 Lille, France.

Email: serge.bourbigot@centralelille.fr 
intense thermal and erosive conditions in jetfires. ${ }^{3}$ It is now applied as a standard to certify the fire performance of passive protection materials used in petrochemical and oil and gas facilities.

In a general manner, fire tests are used in the fire safety field to evaluate the reaction and/ or the resistance to fire of materials. They are usually performed at large scale to capture completely, or as much as possible, the effects of a given fire scenario in terms of thermal exposure and incident conditions such as velocity imparted to the tested system. However, those tests are time-consuming, expensive, and must be performed with specific installations. Facing this situation, preliminary fire tests at reduced scale can be proposed to address this issue and to achieve a better understanding of the fire behavior of materials. ${ }^{4-6}$ Based on previous work ${ }^{7}$ and considering extreme fire scenarios, ${ }^{8,9}$ the motivation was to develop a jet fire facility at reduced scale (or in other words a jetfire lab) to investigate the fire performance of passive protection materials. Jetfire at such reduced scale is scarce in the literature ${ }^{10}$ and a bench-scale test devoted to jetfire scenario does not exist except an attempt by Wighus that developed a bench-scale test to screen materials for final certification preparation. ${ }^{11}$ [AQ: 1]

This article is organized in three parts. The first part is devoted to the development of je fire at a reduced scale based on an experimental approach. The second part deals with the investigation of similitude between the small-scale bench and real-scale jetfire (ISO 228991:2007 "Determination of the resistance to jet fires of passive fire protection materials"). The third part examines the effect of junction in assembled samples on testing.

\section{Development of a small-scale test bench mimicking the jet fire scenario}

The determination of the resistance to jetfires of passive protection materials is described in the dedicated Standard ISO 22899-1:2007. ${ }^{3}$ The goal of this standard is to simulate the thermal and mechanical loads resulting from high-pressure releases of flammable gas, pressureliquefied gas, or flashing liquid fuels for validating the performance to jetfires of PFP. ${ }^{12,13}$ The configuration of the real-scale jet fire facility used in this work is illustrated in Figure 1 (note that different setups are allowed according to the standard). It consists of a propane burner delivering the required heat flux and velocity, a flame re-circulation chamber, and a protective chamber. The sample is installed between two chambers on a $10-\mathrm{mm}$ thickness steel plate. The mass flow of fuel delivered by the propane burner generates high convective and radiative heat fluxes that can reach local heat flux as high as $350 \mathrm{~kW} / \mathrm{m}^{2}$ (total heat flux). ${ }^{14}$ The mass flow rate of the propane is $0.3 \mathrm{~kg} / \mathrm{s}$. Propane is used because it has a greater propensity to form soot as compared to natural gas and it can, therefore, produce a flame of higher luminosity. High erosion forces are generated by releasing the gas jet at sonic velocity, $1 \mathrm{~m}$ away from the sample surface. ${ }^{15}$

The steel plate used during the real-scale jetfire is instrumented using 18 thermocouples placed on its backside (Figure 2). This instrumentation allows to follow the temperature evolution as a function of time during the test at different locations. The criterion of performance is defined by a failure temperature and a critical time for a given material and application. The most common duration in internal configuration are 15, 30,60, 90, and 120 min (higher times are sometimes required for specific applications). The failure temperature is defined according to the requirement for the equipment and the final use of the protection. For example, $400^{\circ} \mathrm{C}$ is used as criteria for load-bearing steel structures. ${ }^{16}$ 


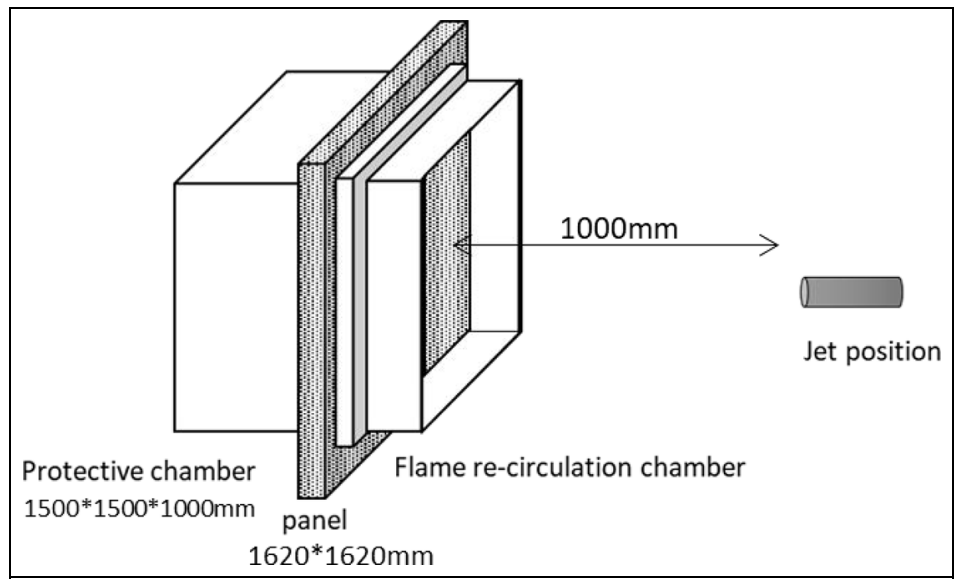

Figure I. Scheme of the setup of real-scale jetfire: internal configuration.

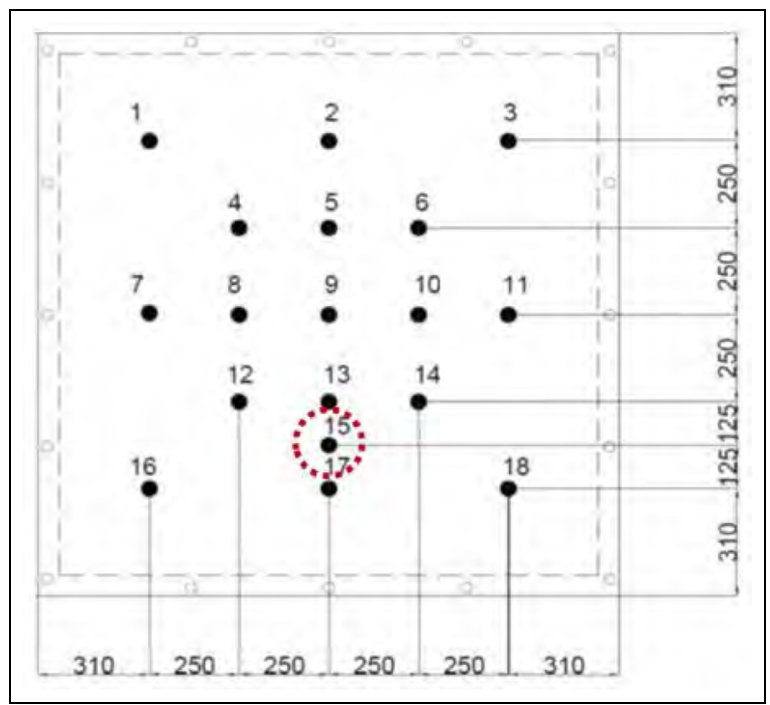

Figure 2. Scheme of thermocouple locations for a given panel test specimen with impact of flame on thermocouple number 15 in internal configuration on standard test (dimensions in millimeters).

Regarding the complexity of this large-scale test for innovation or research and development (R\&D) of a passive protection material (large panels of materials, consumption of propane, time needed for the test, safety ...), the strategy is to develop a bench-scale test to mimic the thermal exposure of the real-scale jet fire based on an experimental approach. It is, therefore, required that the temperatures reached during a test at the real scale on a calibrated sample. The easiest way was to use a virgin steel plate without any PFP material installed as calibration.

On a standard firejet, a hot zone and a cold zone can be distinguished. The latter corresponds to the impact zone of the jet on the plate: the high velocity of the jet creates high 


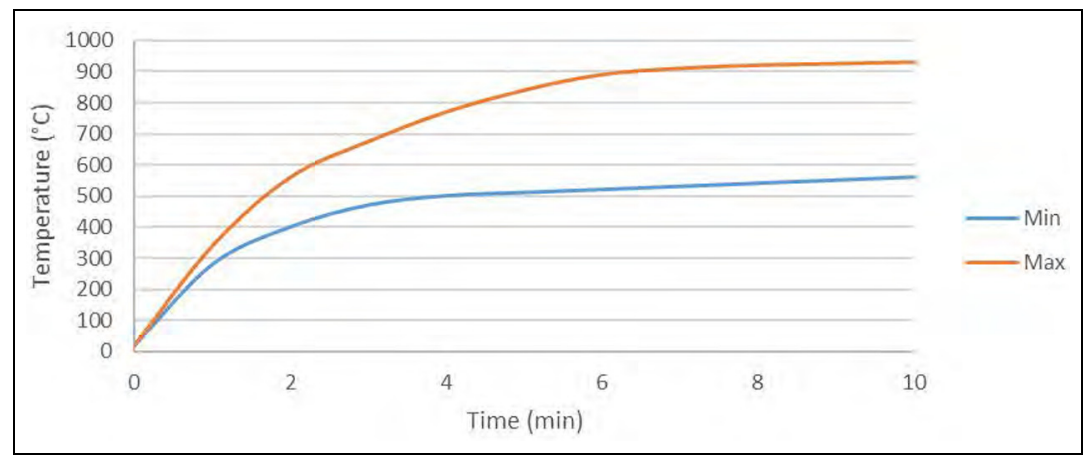

Figure 3. Maximum and minimum temperatures observed on virgin steel plate during real-scale jetfire.

convection at the surface of the plate leading to lowering of temperature. Figure 3 shows the highest and lowest temperatures as a function of time reached during a jet fire test on the backside of the virgin steel plate $10 \mathrm{~mm}$ thick. It was recorded with Inconel thermocouples located on different locations on the back side of the steel plate as shown in Figure 2 and the setup corresponded to an internal configuration of standard test. On testing for $10 \mathrm{~min}$, the temperatures of the steel plate jumped from ambient temperature to about $950^{\circ} \mathrm{C}$ (highest temperature) and from ambient temperature to about $550^{\circ} \mathrm{C}$ (lowest temperature).

In a previous work, a bench-scale test was developed to mimic extreme fire scenarios and deliver heat fluxes from $150 \mathrm{~kW} / \mathrm{m}^{2}$ up to $400 \mathrm{~kW} / \mathrm{m}^{2} .{ }^{17}$ The bench-scale test was not designed initially to provide a correlation with the real-scale jetfire but to examine a specific behavior of intumescent coating undergoing high heat fluxes and permitting a fast temperature rise. It is the starting point of the further development addressed in this article and fully described in Figure 4. The bench-scale test was composed of two parts:

- The part A (Box A) has two functions: (1) flame stabilization and (2) calibration of heat flux.

- The part B (Box B) allows the evaluation of the samples with the application of a calibrated heat flux (enhancement was then applied here as shown in the next section).

A pneumatic cylinder controls Box A to Box B back and forth. To generate the selected heat flux, an "induced air" torch burner $\left(\mathrm{AEM}^{\circledR}\right)$ was used. The pre-mixing air/propane release is fed by two Bronkhorst ${ }^{\circledR}$ flowmeters (volumetric flow for air and mass flow for propane). The burner holder allows modifying the distance between the sample and the burner (from 15 to $25 \mathrm{~cm}$ ), as well as the angle of flame impingement and the impact height. In this initial configuration, Box A was equipped with a gauge for measuring the imparted heat flux using a calibrated heat flux sensor (Sequoia ${ }^{\circledR}$ ) cooled down at $23^{\circ} \mathrm{C}$ (total flux range 50 $400 \mathrm{~kW} / \mathrm{m}^{2}$ and radiative flux range $50-500 \mathrm{~kW} / \mathrm{m}^{2}$ ).

To reach the objective in terms of thermal exposure, heat fluxes higher than $300 \mathrm{~kW} / \mathrm{m}^{2}$ must be applied on the sample exposed surface. On testing, the total heat flux is indeed estimated over $350 \mathrm{~kW} / \mathrm{m}^{2}$, which is consistent with the measurements by Stolen. ${ }^{14}$ Hence, the calibration method needed to be revised because the application of a flame with a high erosion force on the calibrated heat gauge leads to a degradation of the latter and, therefore, it 


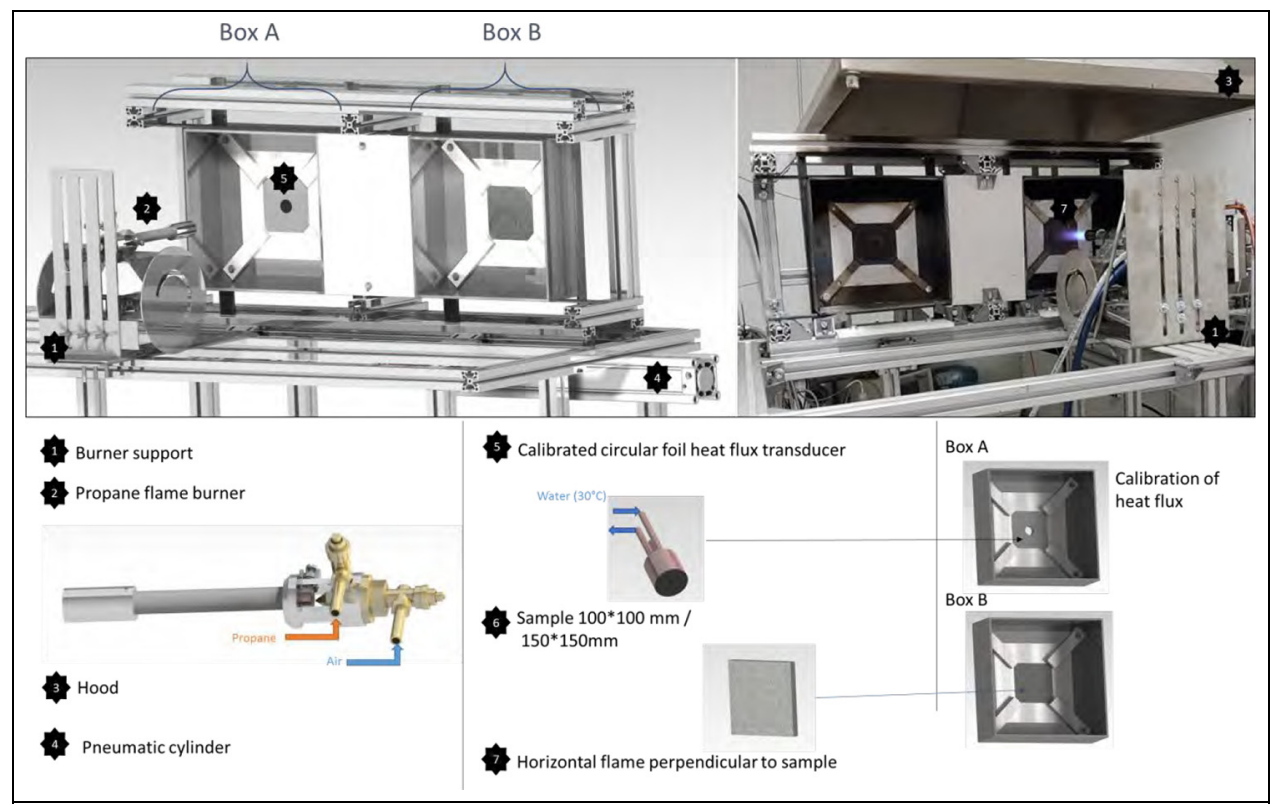

Figure 4. Complete description of Jetfire lab before the enhancement of the boxes $A$ and $B$.

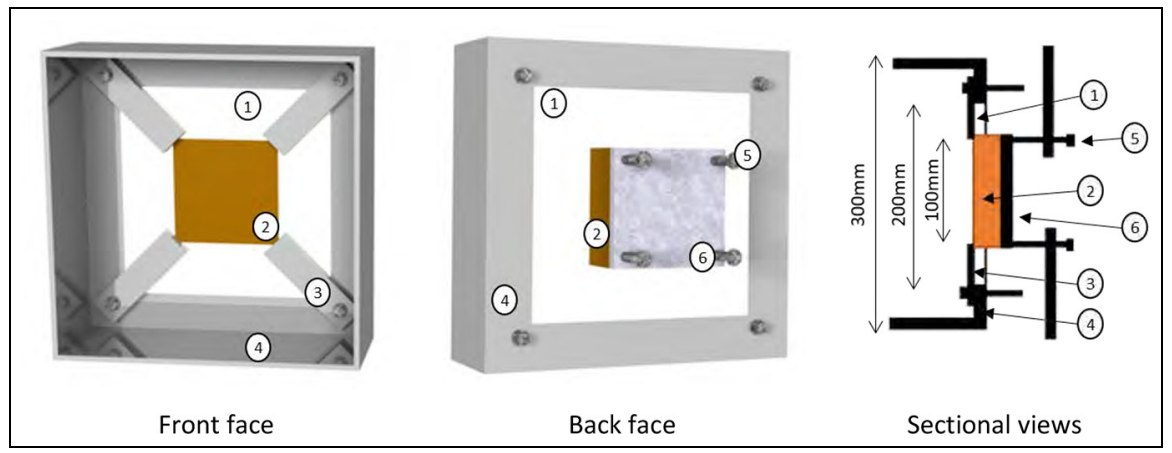

Figure 5. Scheme of Configuration I. I: isolated plate (calcium silicate); 2 : sample $\left(100 \times 100 \mathrm{~mm}^{2}\right)$; 3 : metal bars to hold the sample to the surface; 4: box; 5: screw; 6: steel plate.

makes discrepancies on the measured value. An improved configuration was then designed as follows: (1) Box A was equipped with a steel plate $10 \mathrm{~mm}$ thick, similar to that used during real-scale jetfires, with temperature monitoring on the backside of the plate instead of the heat gauge and (2) the steel plate plays then the role of calibrating sample.

The two boxes were designed in steel (XC40 grade) for the frames and in calcium silicate for the insulation part drilled in its center at the sides of the sample.[AQ: 2 . II $\mathrm{s}$ the, hereafter, called Configuration 1 (Figure 5). With this setup, a sample of dimeisoun of $100 \times$ $100 \mathrm{~mm}^{2}$ and having different thicknesses can be evaluated. The sample is held at the four 


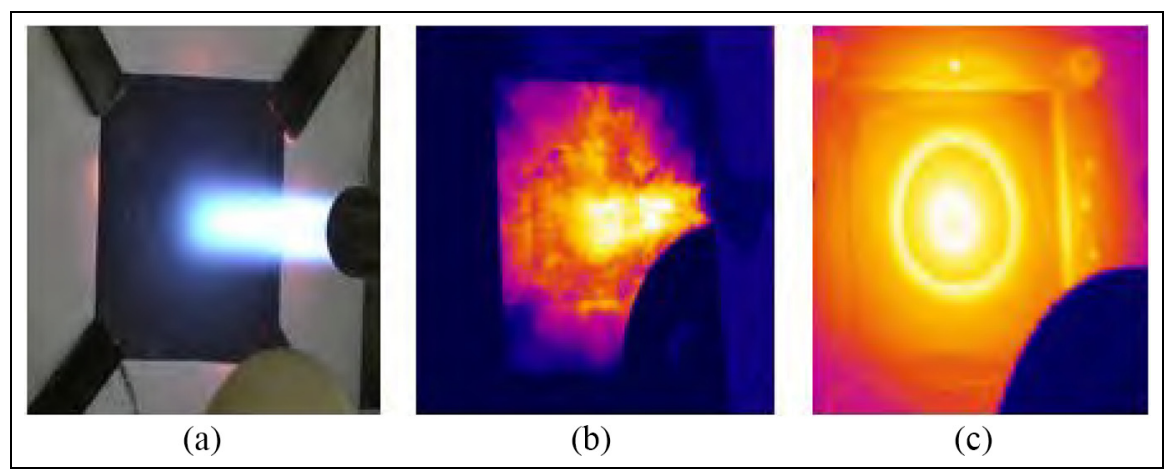

Figure 6. Snapshots during tests with the jetfire lab on virgin steel plate. (a) Conventional camera, (b) infrared (IR) camera with flame envelope filter, and (c) IR camera with through-flame filter.

corners by metal bars on the front side and on the backside, and four screws apply pressure on the steel plate located at the back of the sample.

With Configuration 1, a heat flux with an appropriate propane flow rate (temperature of the flame $<1650^{\circ} \mathrm{C}$, heat flux $>450 \mathrm{~kW} / \mathrm{m}^{2}$ ) was applied on the steel plate. On testing, the thermal and mechanical behaviors of the sample can be observed. An infrared camera (FLIR $\mathrm{X} 6540 \mathrm{sc})$ calibrated for high temperatures $\left(300^{\circ} \mathrm{C}-1500^{\circ} \mathrm{C}\right)$ and equipped with filters was used to examine the surface of the sample (filter through the flame: NARROW-3970_4010 $60 \%$, bandwidth (3970-4010 $\mathrm{nm}$ ) transmission 60\%) and the geometry of the flame (filter envelope of the flame: NARROW-4500_4540 - 70\%, bandwidth $(4500-4540 \mathrm{~nm})$ transmission $70 \%$ ). The deformation (shrinkage, expansion, and cracks) of the sample was recorded by the filtered infrared camera permitting to observe the material through the flame. In addition, the surface temperature of the sample can be estimated assuming its emissivity during the test (generally taken at 0.9 considering a charred material). Figure 6 shows different pictures of operating jetfire lab obtained with conventional video camera (Figure 6(a)) and with an infrared camera equipped with filters (Figure 6(b) and (c)).

Temperature measurements were done on the backside of the sample indirectly with the addition of a metal plate screwed on the backside of the sample to be tested. They were carried out with thermocouples type $\mathrm{K}$ (Chromel/Alumel) and with an infrared camera (backside of steel plate coated with a known emissivity paint equal to 0.92). During the test, surface temperatures ranging between $800^{\circ} \mathrm{C}$ and $900^{\circ} \mathrm{C}$ were reached after 5 min of fire exposure (Figure 7(a)). The mapping of the temperatures recorded by thermocouples welded on the backside of steel plate is shown in Figure 7(b) at $900 \mathrm{~s}$. The largest temperature difference between two thermocouples is not higher than $70^{\circ} \mathrm{C}$. Thus, the temperature field appears to be quite homogeneous. The analysis of the temperature changes clearly shows that the temperature is much higher than that measured in the real-scale jetfire where the difference between the minimum and maximum temperature reaches temperatures higher than $350^{\circ} \mathrm{C}$ at $10 \mathrm{~min}$. It is assigned to a strong heat accumulation inside the box because of the non-conductive plate of calcium silicate.

According to the results above, the test setup must be enhanced to avoid too much heat accumulation inside the box, and hence to limit the temperature rise, which was too fast to mimic the temperature rise at the real scale. The calcium silicate plate was removed and the 


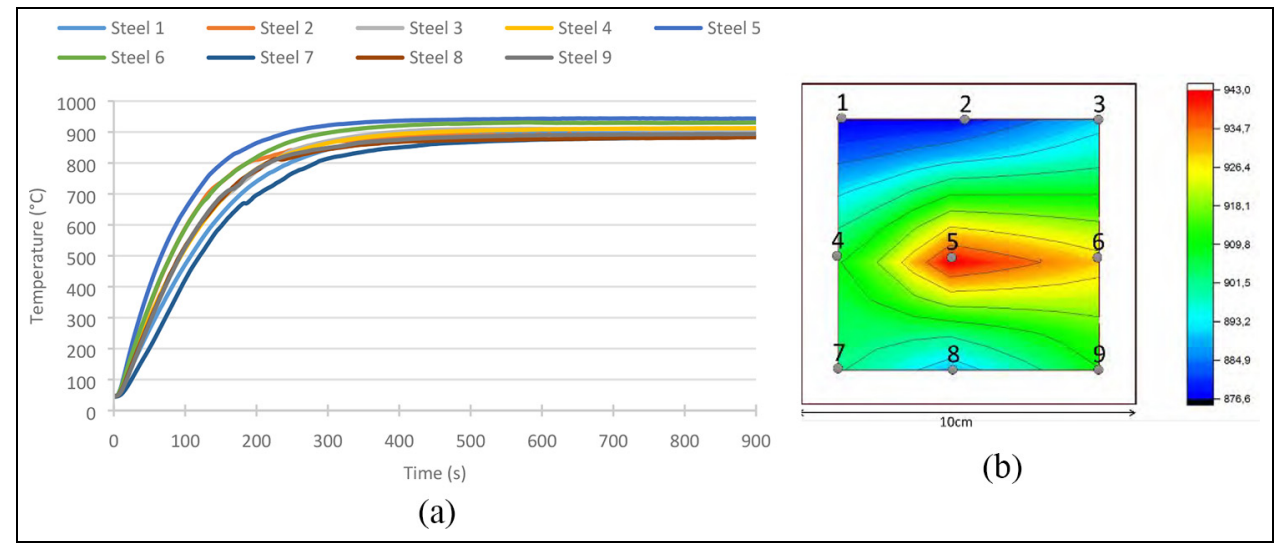

Figure 7. (a) Temperature as a function of time on steel plate $(10 \mathrm{~mm})$ in configuration and (b) temperature mapping at $900 \mathrm{~s}$ obtained with linear interpolation with thermocouples weld on steel plate.

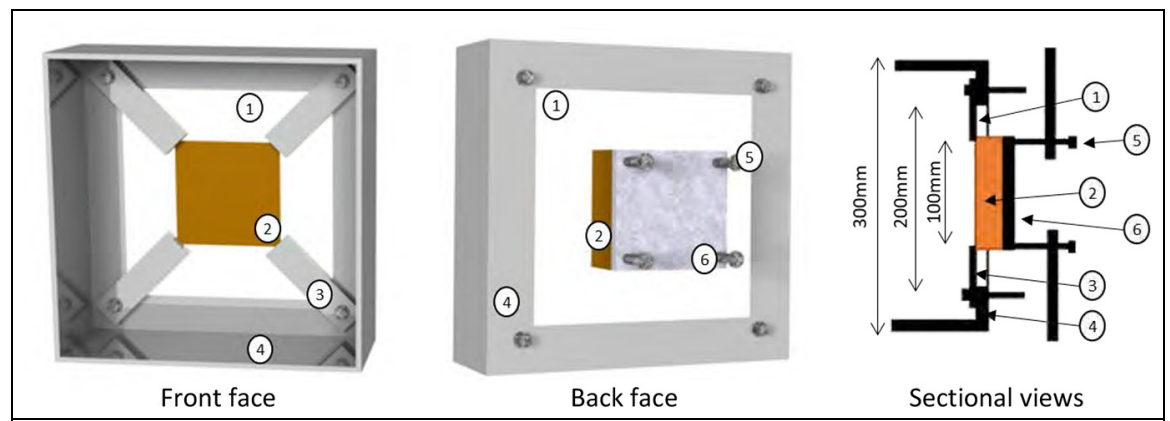

Figure 8. Scheme of the modified Configuration. I: steel frame; 2: sample $\left(I 50 \times 150 \mathrm{~mm}^{2}\right)$; 3: screw; 4 : box; 5: steel plate; 6: recirculation chamber.

box was then only made of metal frame (XC40). It is also worth noting that the real-scale jetfire consists of a metal frame to hold the sample as shown in Figure 8. The second modification of the test setup included applying a similar homogeneous mechanical stress on the edges of the sample (as in the real-scale jet fire) where the material is held between the two boxes (Figure 1). It was achieved by sandwiching and screwing the sample between a steel plate and steel frame (20 $\mathrm{mm}$ on the edges of the sample): the mechanical stress applied on the sample with the through screws is homogeneous over the whole sample. The sample (or calibration system) of dimensions $150 \times 150 \mathrm{~mm}^{2}$ was positioned in the center of the box with an exposure window to the flame equivalent to $110 \times 110 \mathrm{~mm}^{2}$. This configuration also permits more flexibility to evaluate different thicknesses of samples.

With the modified configuration, the calibration of the flame temperature was done to reach $900^{\circ} \mathrm{C}$ on the hottest spot of the backside of the steel plate as shown in Figure 9(a). The temperature at $900^{\circ} \mathrm{C}$ on the backside is also plotted (Figure 9(b)). The difference between the highest and the lowest temperature is in the range of $550^{\circ} \mathrm{C}$, between a 


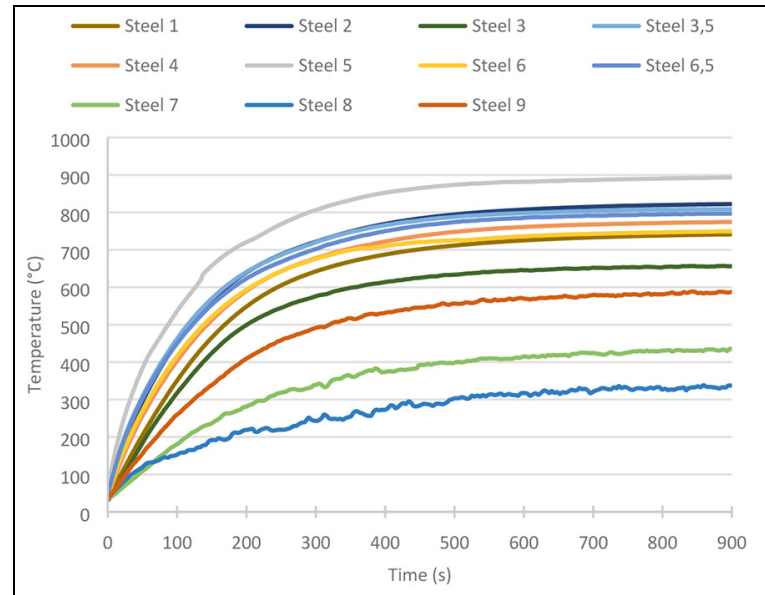

(a)

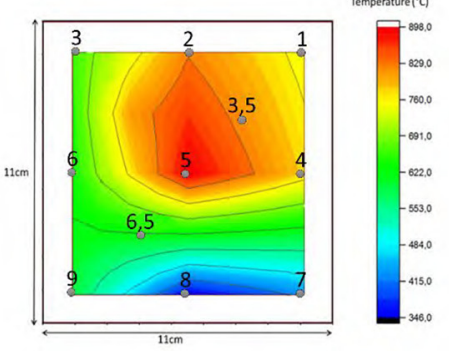

(b)

Figure 9. (a) Temperature as a function of time on steel plate $(10 \mathrm{~mm})$ and $(\mathrm{b})$ temperature distribution at $900 \mathrm{~s}$ on steel plate.

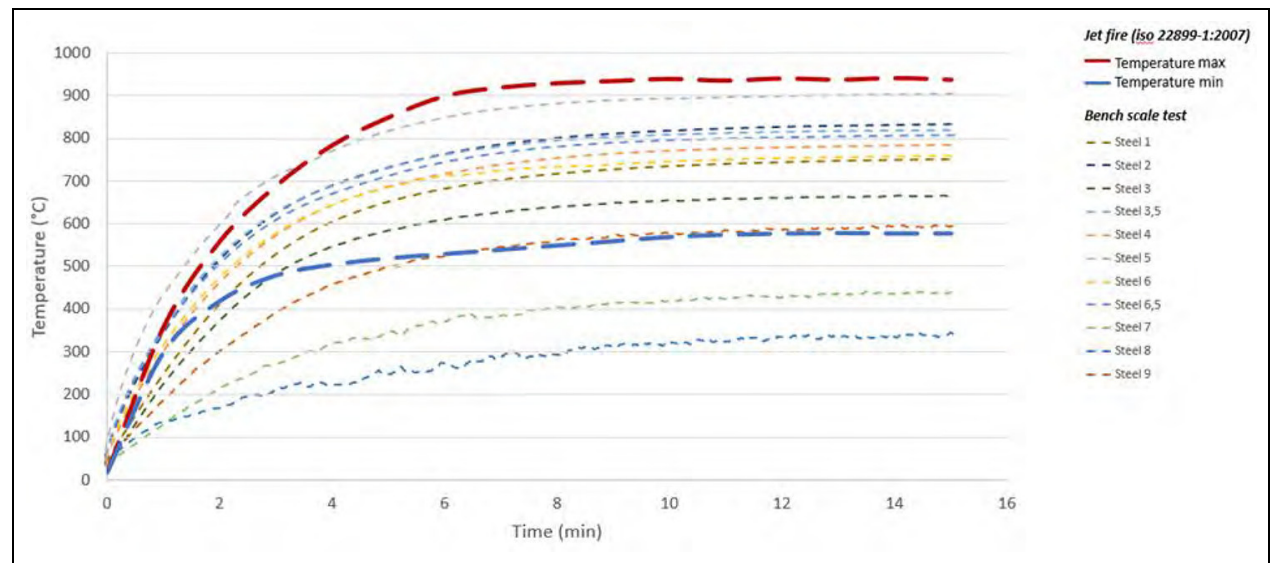

Figure 10. Comparison of the minimum and maximum time/temperature curves measured at the bench-scale and the large-scale jetfire.

minimum value of $300^{\circ} \mathrm{C}$ and a maximum value of $900^{\circ} \mathrm{C}$. The highest temperatures are located in the center of plate unlike the jet fire test where the impact zone is located on the third height of the sample and the lowest temperatures are located at the bottom of the plate because of high heat loss generated by the contact of the steel plate with the steel structure.

Temperature as a function of time measured at the reduced and large scales were compared in Figure 10. Only minimum and maximum temperatures recorded in the large-scale test are plotted to avoid a too busy graph. Similar trends are observed and it can be concluded that jetfire lab can capture the temperature range involved in the real-scale jetfire. It 


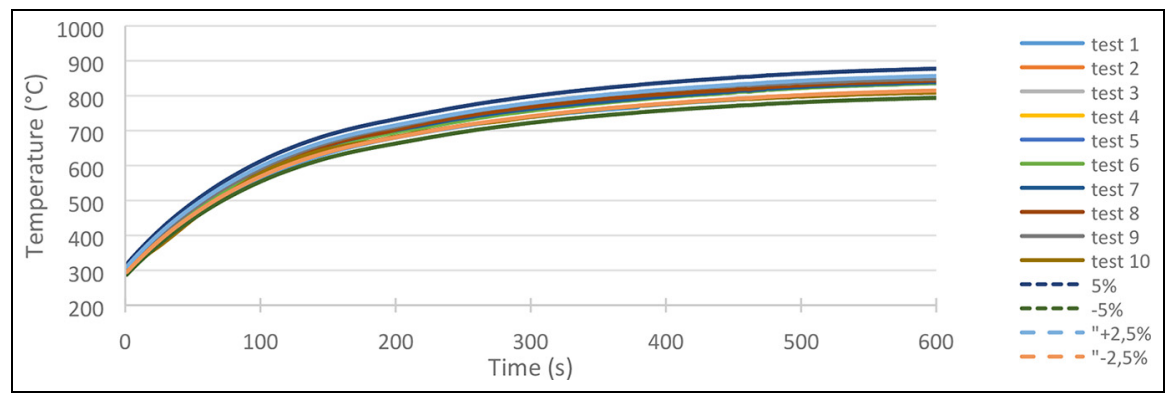

Figure I I. Repeatability of temperature rise on steel plate on calibration step of bench-scale test (Box A).

is also observed for the other zones except for temperatures monitored at the bench in the zones defined by thermocouples 7 and 8 because of their location at the bottom of the plate where heat loss is high.

A test protocol is addressed as a final step of the development to ensure the repeatability of the applied heat flux on the sample. To do so, a propane-air premixed flame is applied on a $10-\mathrm{mm}$ thick conditioned steel plate with a thermocouple (type $\mathrm{K}$ ) welded on the center on the backside of the steel plate. The structure of steel can be changed because of cycles heating up and cooling down the material. However, its thermal properties (e.g. thermal conductivity) depend on its microstructure. ${ }^{18}$ The heating step permits to transform the whole microstructure in austenite and the rapid quenching of hot steel enables the microstructure to be frozen in martensite. This step allows to obtain the most robust microstructure and, therefore, to have highly repeatable measurements. Figure 11 shows several tests performed on steel plate evidencing the high repeatability of the protocol $( \pm 2.5 \%)$.

Jetfire lab is now completely set but it has to be validated through an application involving a representative PFP material. In this work, panels made from the Zaltex-based composite material were considered. Hutchinson manufactures these panels using a unique cellular thermosetting matrix reinforced with basalt fiber resulting as PFP. When making a comparison with other PFP solutions such as intumescent and wet-applied coatings, Zaltex, via its panel state, makes it much easier to install. Junction between panels have to be fully taken into consideration when testing the Zaltex solution, as Zaltex is adjustable including number of layer(s), density, and so forth.[AQ: 3] A irst version, hereafter called "reference A" was examined. The failure temperature was set at $427^{\circ} \mathrm{C}$ for a duration of $1 \mathrm{~h}$. This temperature of $427^{\circ} \mathrm{C}$ corresponds to the temperature at which the steel begins to lose strength in a significant way but keeps enough strength since the microstructure of steel is not significantly modified at this temperature. ${ }^{19}$ Figure 12 shows the location of the thermocouples on the backside of the samples used at the bench scale and the impact area of the flame in the center (red circle).

Figure 13 shows temperature changes as a function of time for reference A performed in duplicate (references A1 and A2). Temperatures increase rapidly up to the failure temperature criteria. The temperature gradient on the backside of the sample is about $150^{\circ} \mathrm{C}-180^{\circ} \mathrm{C}$ at $1200 \mathrm{~s}$. Note that this gradient is slightly higher when reaching the failure temperature. The failure temperature $\left(427^{\circ} \mathrm{C}\right)$ for the samples A1 and A2 is reached at 1432 and $1266 \mathrm{~s}$, respectively, and those times are, therefore, repeatable (deviation of about 6\%; Figure 13(c)). 


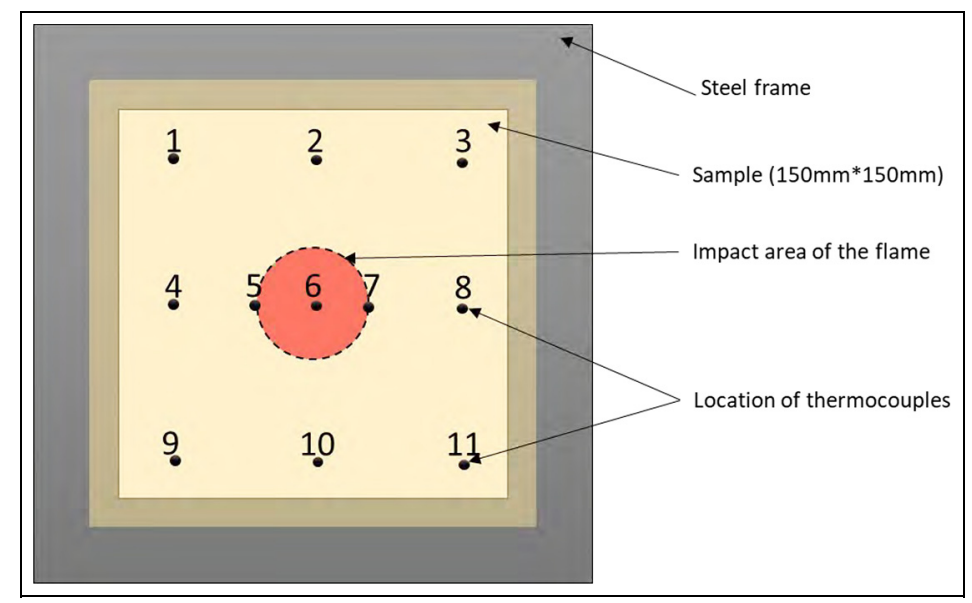

Figure 12. Location of thermocouples on the backside of sample at the bench-scale jetfire.

For the two references (Figure 13(a) and (b)), the thermocouple T6 reaches the failure temperature first. It makes sense as it is located at the impact zone of the burner. This test evidences the repeatability of the reduced-scale jetfire and it also predicts the test should fail at the large scale.

\section{Similitude between lab-scale and real-scale jetfire}

The previous section has defined a robust experimental protocol at a small scale. The goal is to provide a direct comparison between the tests performed at the reduced scale and at the real scale. Reference A was evaluated using the large-scale jetfire at Efectis laboratory, France. Figure 14 shows the location of the thermocouples on the backside of steel plate (note that the steel plate was stuck on the sample as required by the standard for internal configuration). It is noteworthy that the sample at the bench scale was made in a plain part while that installed on the large scale was the assembly of two parts. Indeed, when the PFP material is in the form of a panel, the standard requiring at least one joint shall be included in the panel; while for paints, no junction is required during the test. The total dimension of the panel is $1620 \times 1620 \mathrm{~mm}^{2}$ and the flame re-circulation chamber have nominal dimensions of $1500 \times 1500 \mathrm{~mm}^{2}$. In this last case, unlike the standard, the junction here is horizontal and not vertical: the upper part is a panel of $1500 \times 500 \mathrm{~mm}^{2}$ and the lower part is a panel of $1500 \times 1000 \mathrm{~mm}^{2}$. The flame impingement is located at one-third the height of the sample, and at the center of the length of the sample. The thickness of the two samples $(21 \mathrm{~mm})$ is the same as those used at the small scale.

Time/temperature curves measured during the real-scale jetfire test are shown in Figure 15(a). The temperature at which the failure is detected, was reached after $540 \mathrm{~s}$ (thermocouple 5) and hence, the test failed as predicted in the previous section. Depending on the location of the thermocouple, the measured temperatures exhibit high differences: the highest temperature difference between two thermocouples is close to $450^{\circ} \mathrm{C}$. A direct comparison between the tests at the two scales shows a huge time difference to reach the failure temperature (540 s vs 1432 s; Figure 15(b)). Direct visual comparison between the two scales is also 


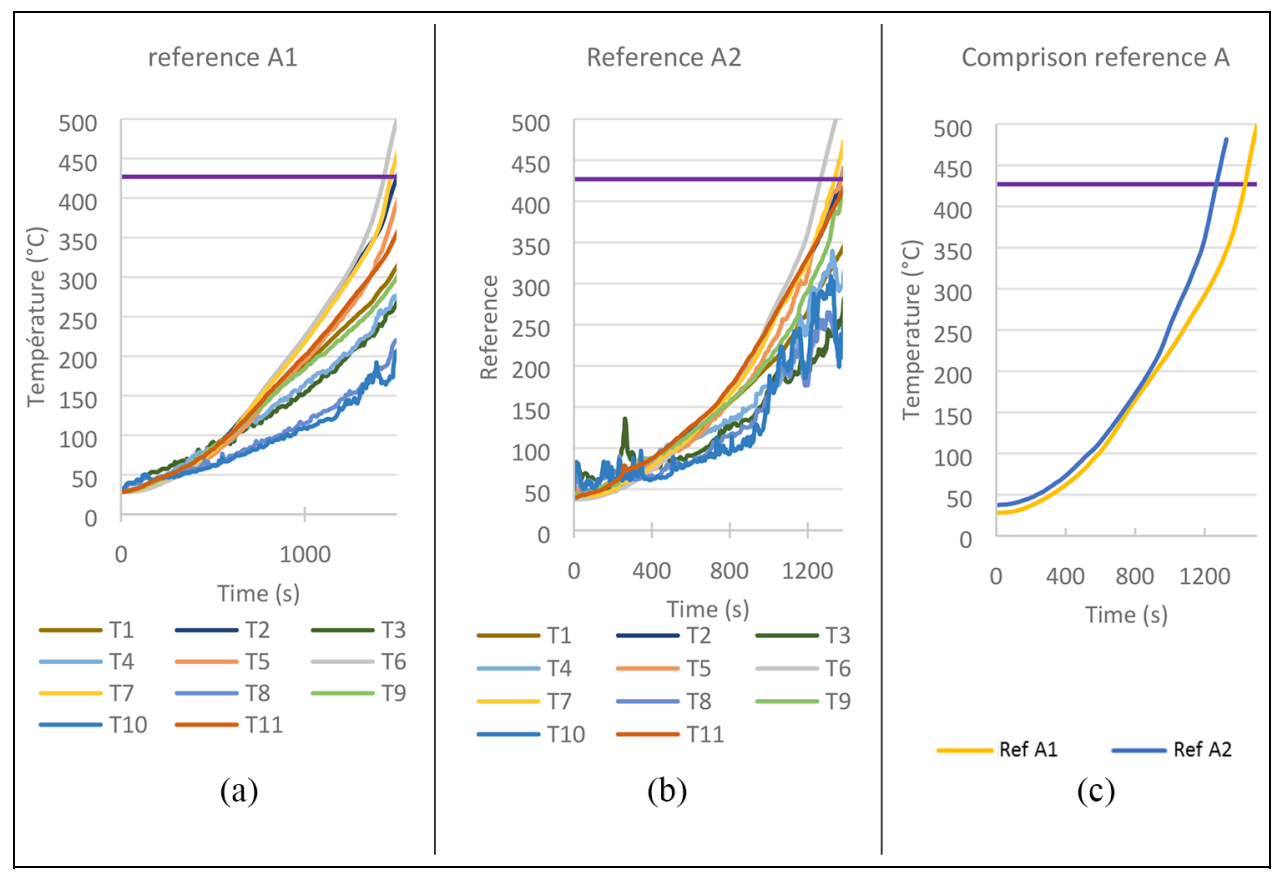

Figure 13. Temperature as a function of time of the references (a) AI and (b) A2, and (c) comparison at the bench-scale jetfire.

impossible because at the large scale, only fireball created by the impingement of the highvelocity jet on the material and rocketing debris can be seen. However, careful observation of the sample after testing provides additional insights (Figure 16). The junction area between the two parts caused the whole sample to fail, which led to a failure zone corresponding to the rapid temperature rise recorded (see the location of thermocouple 5 indicated in Figure 14).[AQ: 4] $\ldots 1$; also consistent with the rapid temperature rise of thermocouples 4 to 11 located close to win junction of the sample.

Figure 17(a) shows the time/temperature curves as a function of time and of the location of thermocouples. Three zones can be distinguished according to the areas: (1) area A is located close to the junction and the temperature rise starts after $300 \mathrm{~s}$ and temperature rapidly reaches $300^{\circ} \mathrm{C}$ at $500 \mathrm{~s}$; (2) area $\mathrm{B}$ is around the area $\mathrm{A}$, the temperature starts after 300 $\mathrm{s}$ and the highest temperature reached in this zone is about $250^{\circ} \mathrm{C}$ at $600 \mathrm{~s}$; and (3) impact zone where the temperatures are the lowest and only reach $100^{\circ} \mathrm{C}$ at $600 \mathrm{~s}$. Regarding this observation, the comparison of the tests at the two scales is addressed in terms of temperature/time curves recorded in the area away from the junction, that is, close to the burner area. In Figure 17(b), those curves were compared to the maximum temperatures recorded at the reduced scale (note a translation of the origin to get an accurate comparison). The same trend between the large- and bench-scale tests is observed evidencing the reliability of our approach.

Based on previous results, a new multilayered sample was designed to improve the resistance against erosion, it is referred as "C." A coating at the surface paired with an erosion 


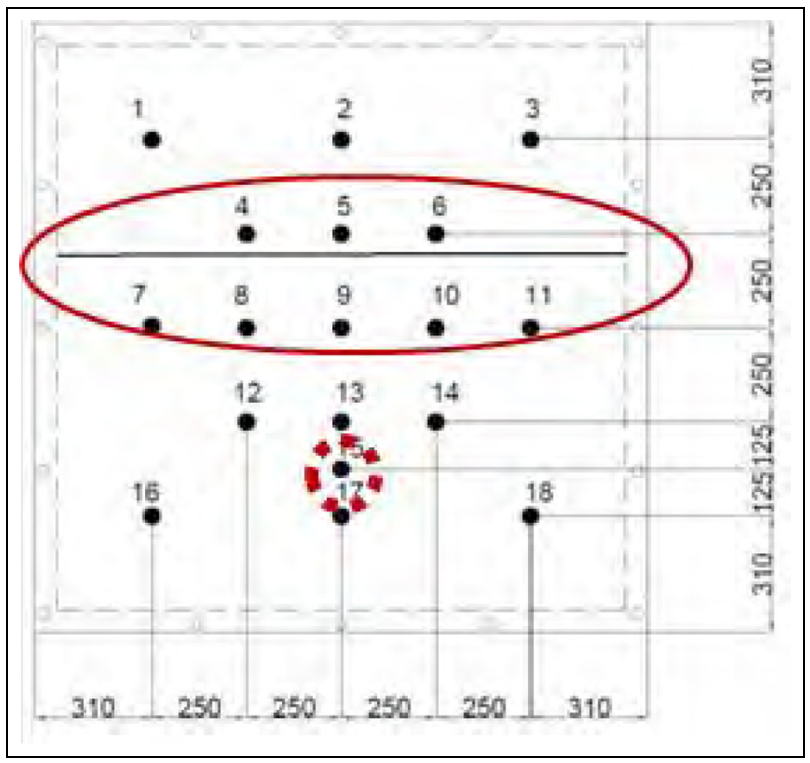

Figure 14. Location of thermocouples on the backside of steel plate of the sample (thermocouples welded on the steel plate stuck on the sample) at the large-scale jetfire.

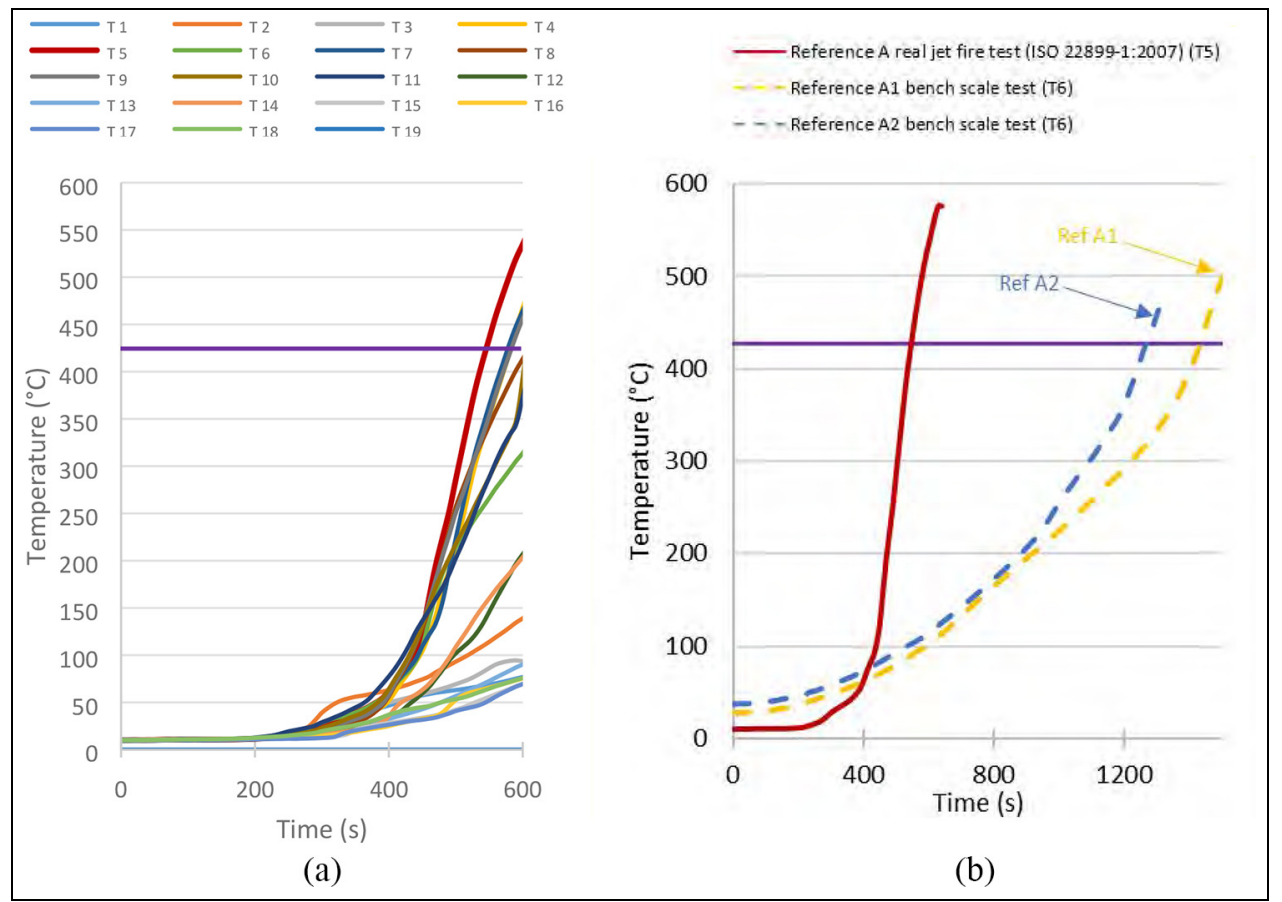

Figure I5. (a) Time/temperature curves recorded during the large-scale jetfire and (b) comparison between bench scale and large scale of the time/temperature curves recorded at the location reaching the failure temperature (shortest times were selected). 


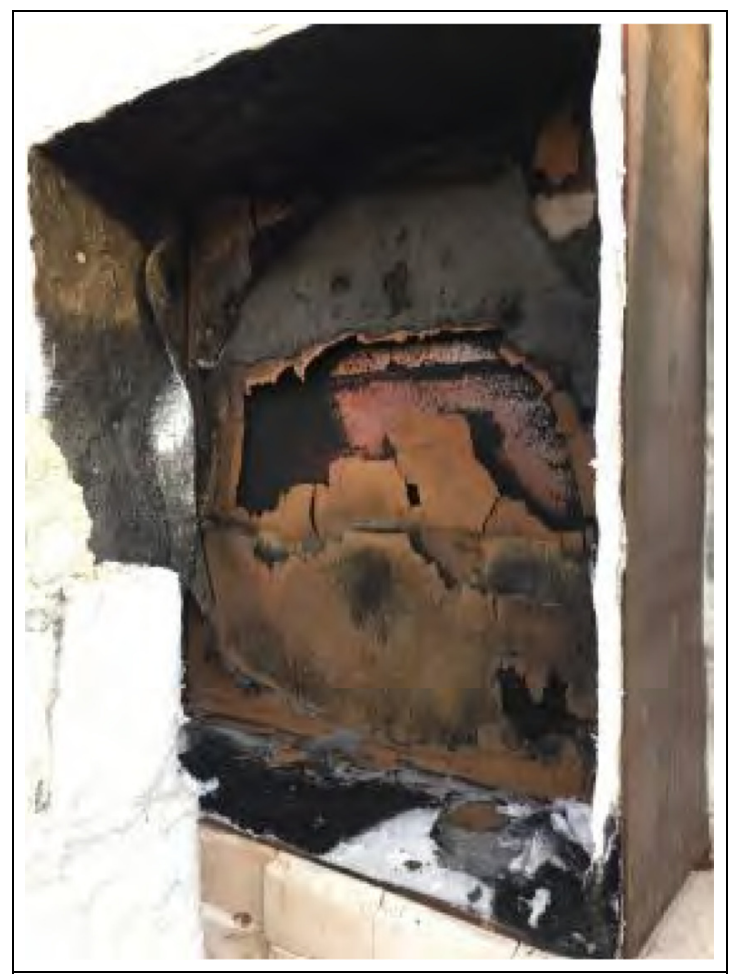

Figure 16. Picture after the large-scale jet fire test performed at Efectis, France.

preventing layer was added. Time/temperature curves recorded at the bench scale are shown in Figure 18(a). The temperature rise (measured on the backside of steel plate) is similar at all locations up to $1000 \mathrm{~s}$ and the temperature gradient in steady state is as low as $65^{\circ} \mathrm{C}$. The fire behavior of the sample is also shown in Figure 18(b). Even though the erosion of this additional layer was observed before reaching $10 \mathrm{~min}$, there was no further damage after $1 \mathrm{~h}$ of testing.[AQ: 5] It sroves that the additional layer provides the required protection. No thermocouple reacneu the critical temperature and it is, therefore, predicted that reference $\mathrm{C}$ should be passing the large-scale jetfire.

After evaluating reference $\mathrm{C}$ at the bench scale, the material was then tested at the real scale. The junction between the two parts of the sample was identified as the weakness zone of the assembly (Figure 19). Considering this observation, the assembly of the panels was modified in an assembly of four panels instead of two, permitting a better control of the assembly and the use of a seal. The dimensions of the four panels were: panel A: $1060 \times$ $1060 \mathrm{~mm}^{2}$, panel B and C: $1060 \times 560 \mathrm{~mm}^{2}$, panel D: $560 \times 560 \mathrm{~mm}^{2}$. On top of this first layer, a second layer with a single vertical junction and a third one on the same configuration as the first layer are fixed (Figure 19(b)). The total thickness of the sample was $27.3 \mathrm{~mm}$. The jet impact was located at one-third the height and at the center of the length of the sample as required by the standard, and the recording thermocouples are located as shown in Figure 19(a).

Figure 20(a) shows the temperature/time curves recorded during the real-scale jetfire. As the critical temperature of $427^{\circ} \mathrm{C}$ was not reached after $1 \mathrm{~h}$, the time of testing was extended 


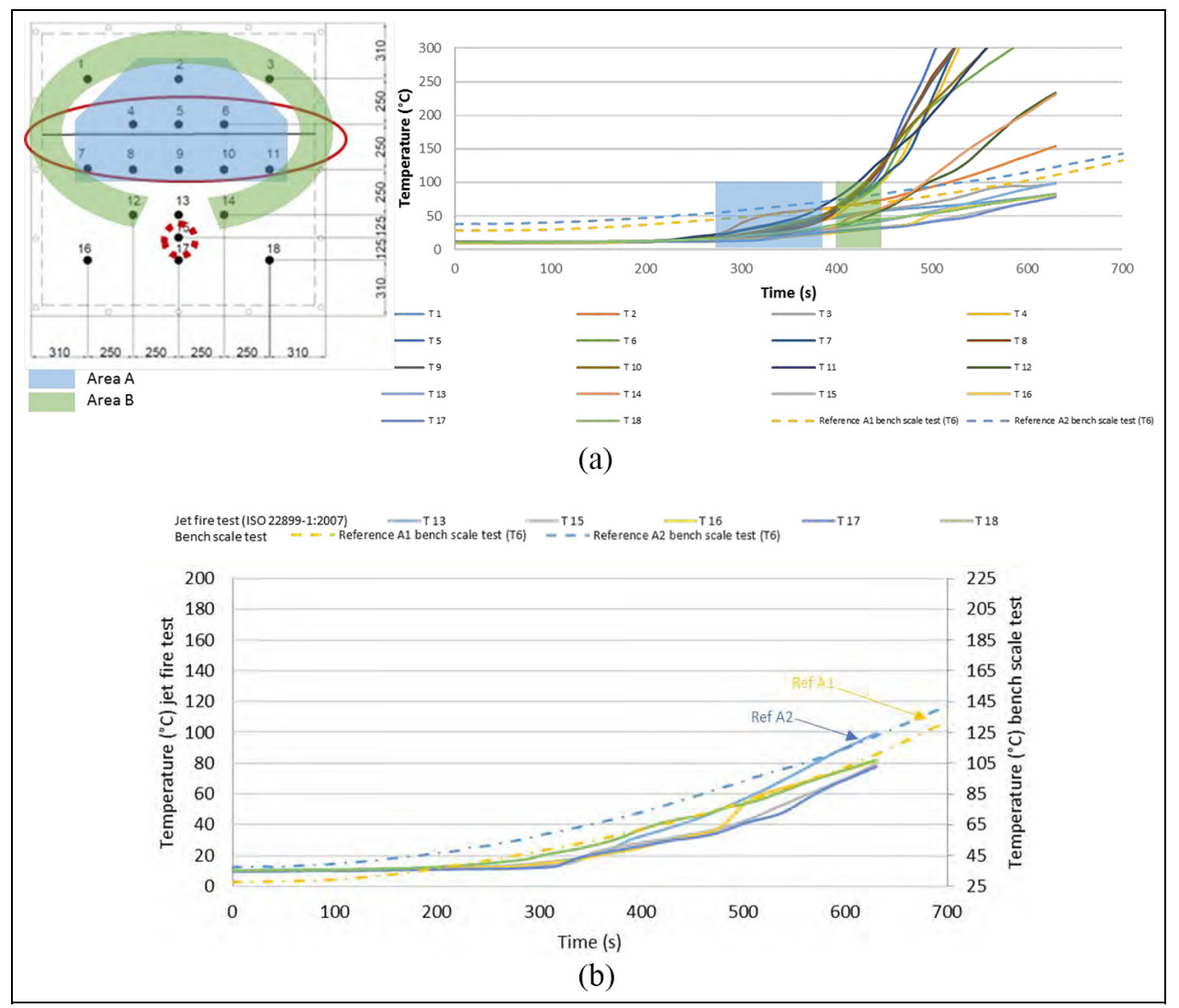

Figure 17. (a) Time/temperature curves (right) as a function of the different areas (left) at the large scale and (b) comparison of the time/temperature curves recorded at the bench-scale and large-scale jetfire away from the junction area.

to $2 \mathrm{~h}$. It is observed that the maximum temperature reached by any sensor always remains below $400^{\circ} \mathrm{C}$. The temperature gradient on the backside of the sample is $130^{\circ} \mathrm{C}$ at $1 \mathrm{~h}$ and $2 \mathrm{~h}$, while it is the highest at $1.4 \mathrm{~h}$, that is, equal to $180^{\circ} \mathrm{C}$. Maximum temperatures were recorded with thermocouples $\mathrm{T} 4, \mathrm{~T} 8$, and $\mathrm{T} 12$, which are located at the junctions between plates. Maximum temperatures as a function of time observed at real scale (T4) and at bench scale (T5) were superimposed as seen in Figure 20(b). The maximum value measured at the bench scale was $290^{\circ} \mathrm{C}$ while it was $405^{\circ} \mathrm{C}$ at real scale. The difference between the maximum temperatures was quite high between the two tests ( $40 \%$ difference at $80 \mathrm{~min})$. The analysis of the sample after testing reveals the opening of the vertical junction (Figure 21).

At the large scale, the vertical junction of the assembly is the weakness zone of the system as specified in the dedicated standard. Considering this zone, no correlation can be found between the two scales. The highest and lowest temperatures recorded at the real scale were then compared to those measured at bench scale (Figure 22(a)). All curves exhibit the same shape. In the steady state, the temperatures at the bench scale are similar to those measured at the large scale. At shorter times, temperatures at the bench scale start increasing faster than those at the large scale. It can be explained as follows: 


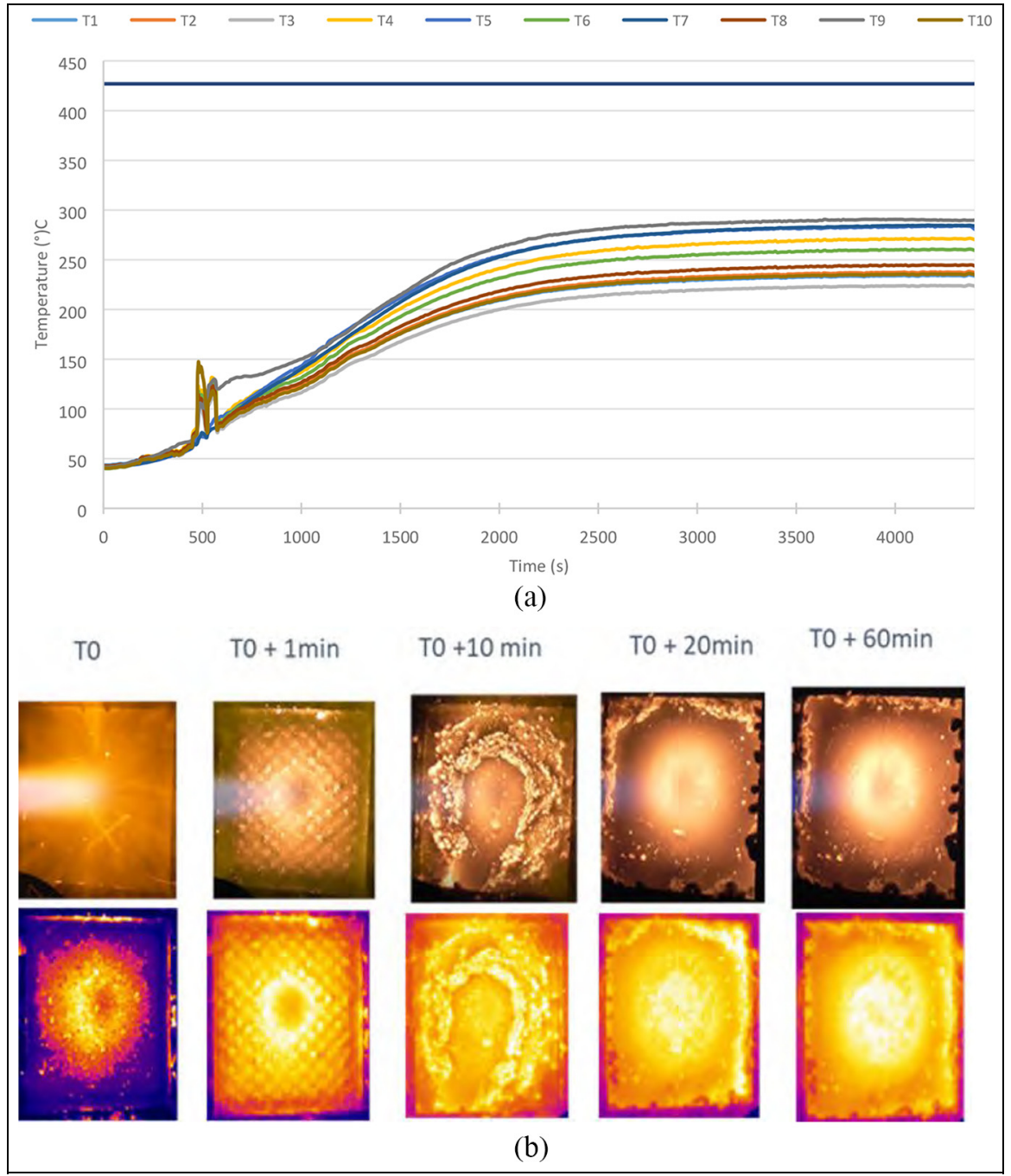

Figure 18. (a) Time/temperature curves measured on the backside of steel plate stuck on the sample and (b) fire behavior during the test at the bench scale for reference $C$.

(1) The difference in heat propagation at the two scales: in the jetfire lab, heating is mainly located in the center because of the burner impact zone while at the large scale, the fire impingement is above the impact zone. In addition, the heat dissipation is higher at the large scale because of high convective effect (high jet velocity at the surface creating high convection) than that in the jetfire lab.[AQ: 6]

(2) The erosion on the sample due to the combination of flame impingeme ind high temperature located in the center of the sample, which is stronger at the lab scale compared to the real scale. 


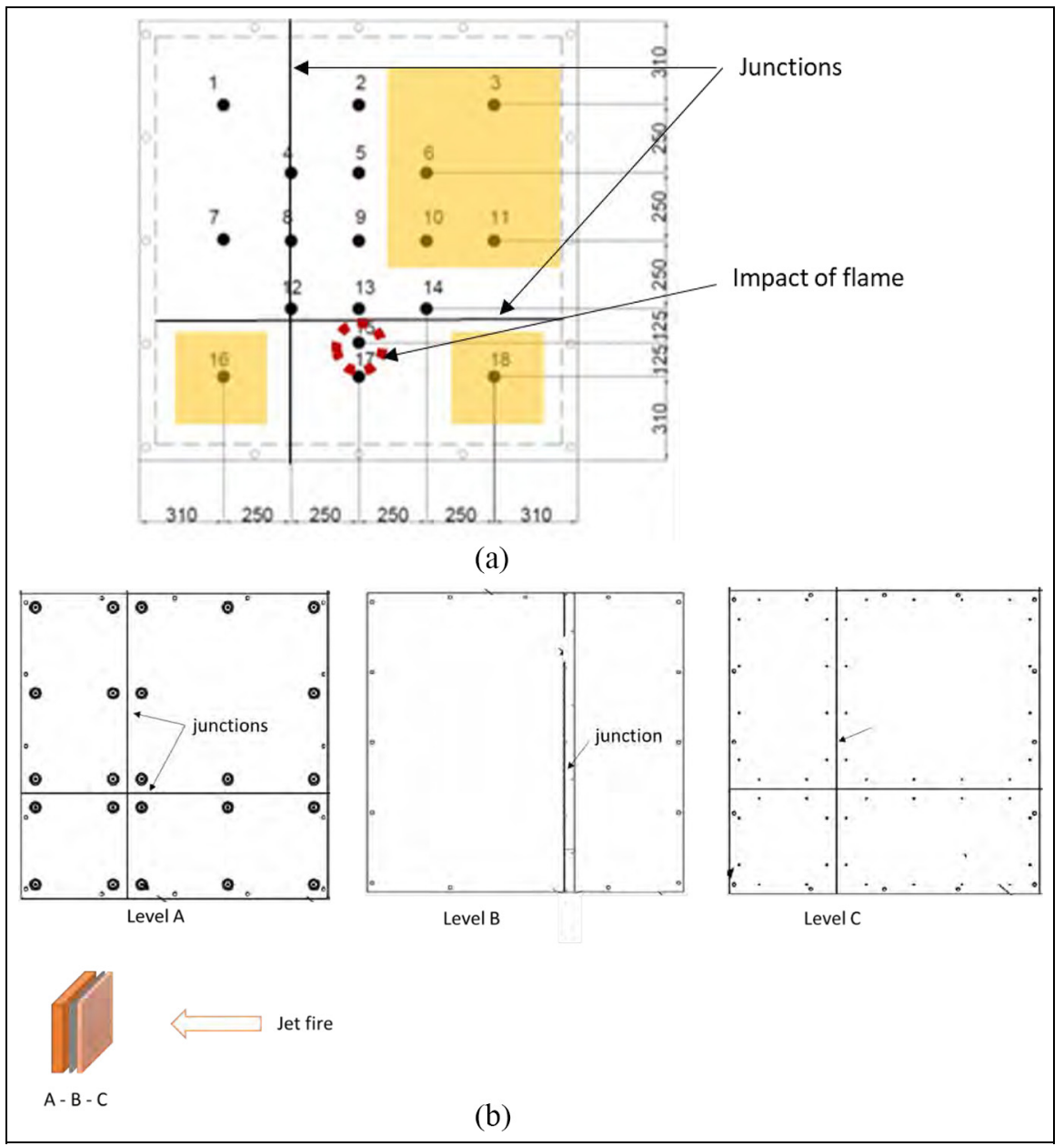

Figure 19. (a) Location of the thermocouples and the flame impingement area (red circle) on the sample at the large scale including the comparison zones (TI3-T6-TI0-TII-TI6-TI8 in orange squares) view from the backside. (b) Assembly of the three layers of the sample view from the backside for large-scale jet fire test.

The last assumption is supported by the temperature rise corresponding to the piercing of the first insulating layer. If the plot of Figure 22(b) is zoomed in (Figure 22(b)), a steep slope break is observed at around $470 \mathrm{~s}$ for the temperatures measured at the bench scale. It is not observed at the real scale as only a smooth slope break is measured at $600 \mathrm{~s}$.

\section{Study of the junction on the sample}

The above section clearly evidenced that the brittleness of the junction created an additional temperature rise on testing. In this part, the objective is to mimic the effect of the junction at the bench scale. A vertical junction was made on the small-scale samples (Figure 23(a)) 


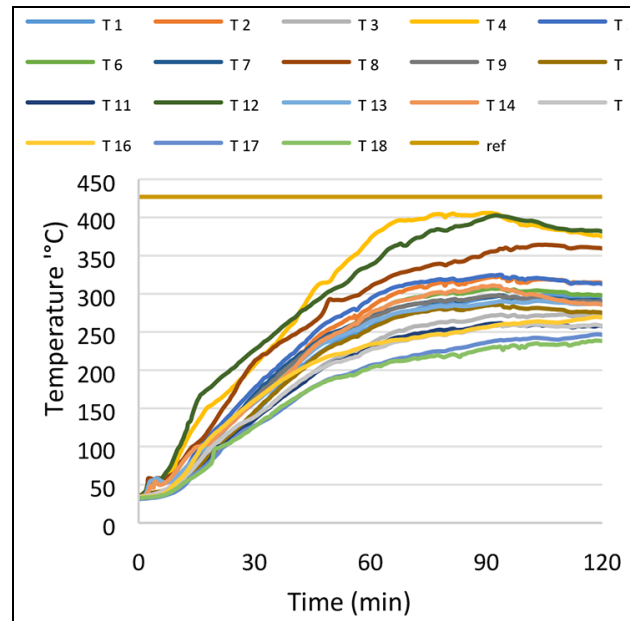

(a)

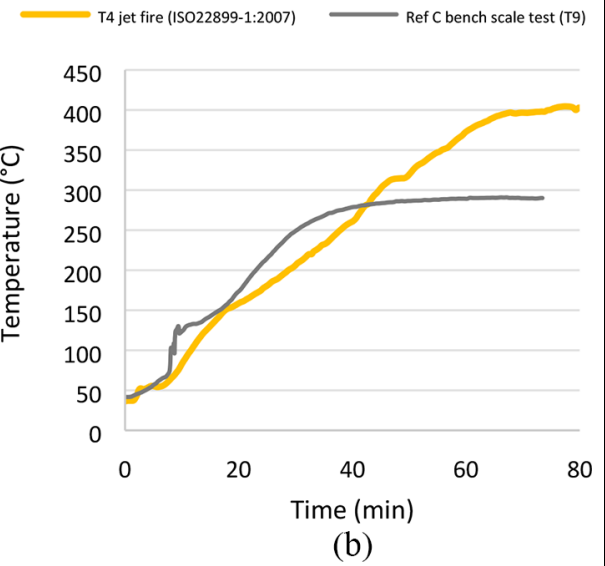

(b)

Figure 20. (a) Time/temperature curves of reference $C$ at the real-scale jetfire and (b) comparison between bench-scale test and real-scale jet fire at two selected locations of time/temperature curves.

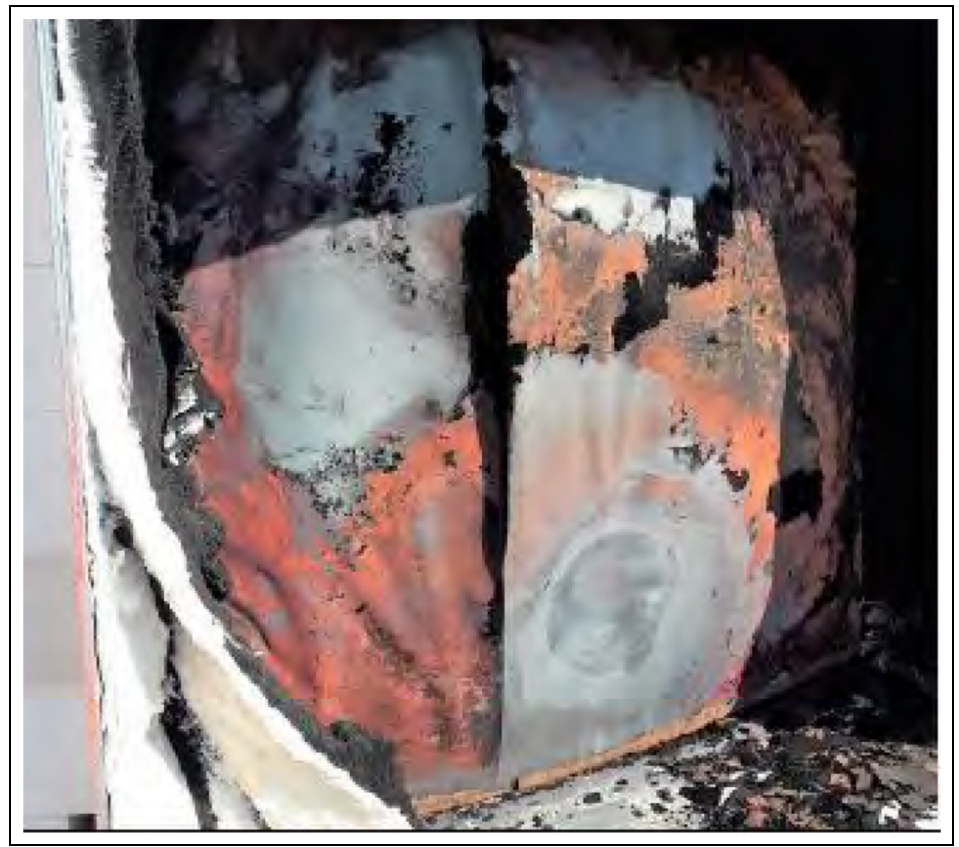

Figure 2I. Photo taken after the real-scale jet fire test for reference $\mathrm{C}$. 


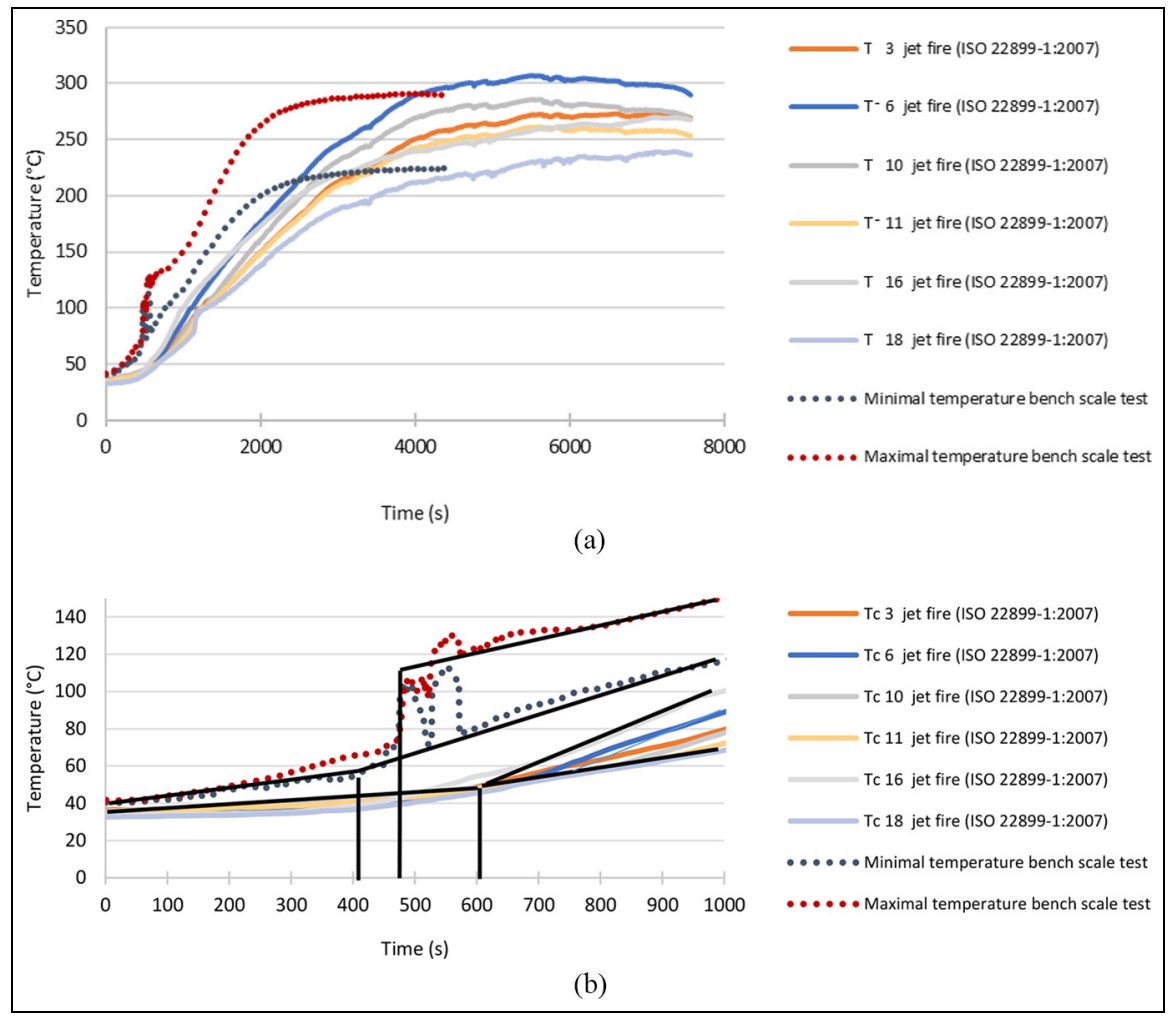

Figure 22. (a) Location of thermocouples on the backside of the sample (reference $C$ ) at the real-scale jetfire including the comparison zones (TI3-T6-TI0-TII-TI6-TI8 in orange squares). (b) Comparison of time/temperature curves between bench scale and real scale on the full-time scale. (c) Comparison of time/ temperature curves between bench scale and real scale between 0 and $1000 \mathrm{~s}$.

including a junction located in the horizontal third of the sample as done at large scale (Figure 23(b)).

Figure 24 illustrates the temperature/time curves on the backside of the sample with a junction on testing at the bench scale. The results are gathered according to the three areas shown in Figure 23(b). In the area A located at the left of the vertical junction, the timetemperature curves exhibit temperature peaks between 450 and $1460 \mathrm{~s}$ of exposure. This phenomenon is attributed to the thermal decomposition of the seal creating an additional heat release (seal in silicone). The maximum temperature recorded is $262^{\circ} \mathrm{C}$. In the area $\mathrm{B}$ located at the right of the vertical junction, the time/temperature curves increase smoothly and slight perturbation is observed because of the thermal decomposition of the seal. The maximum temperature recorded is $367^{\circ} \mathrm{C}$, that is, $40 \%$ more than that measured in the area $\mathrm{A}$. It is related to the flame impingement. The area $\mathrm{C}$ corresponds to thermocouple $\mathrm{T} 3$, $\mathrm{T} 8$, and $\mathrm{T} 11$ located at the right of the zone B (for the sake of clarity of Figure 24(c), only T3 was shown). As in the area B, the time-temperature curve increases smoothly and only slight perturbation is observed because of the thermal decomposition of the seal. The maximum temperature recorded in this zone is $235^{\circ} \mathrm{C}$ and the temperature changes are similar to those 


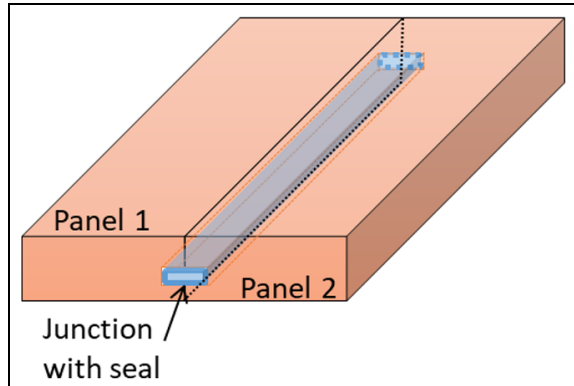

(a)

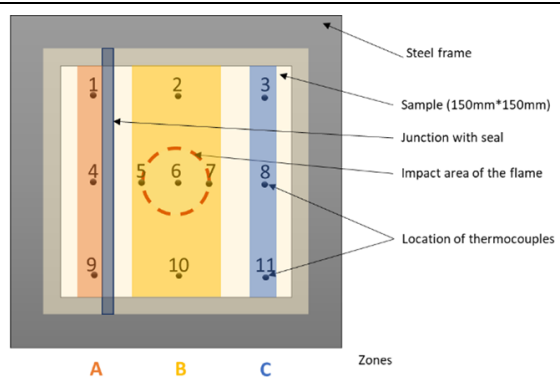

(b)

Figure 23. (a) Scheme of type of junction used on jet fire test and (b) location of the thermocouple on the sample (reference C) made with junction at the bench scale.

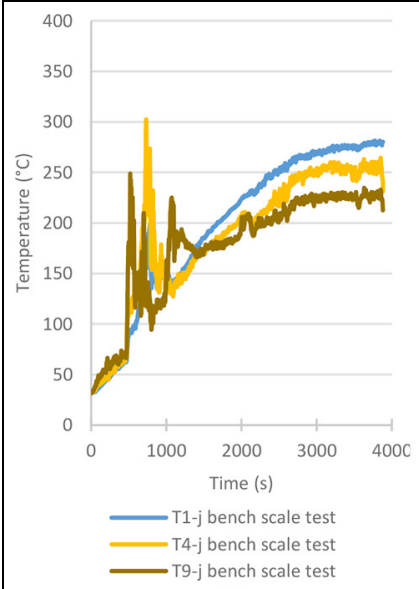

(a)

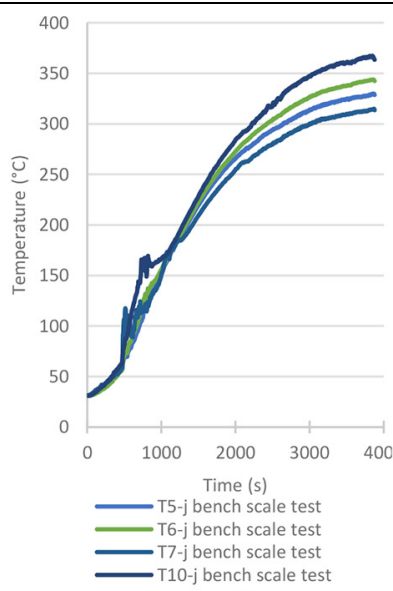

(b)

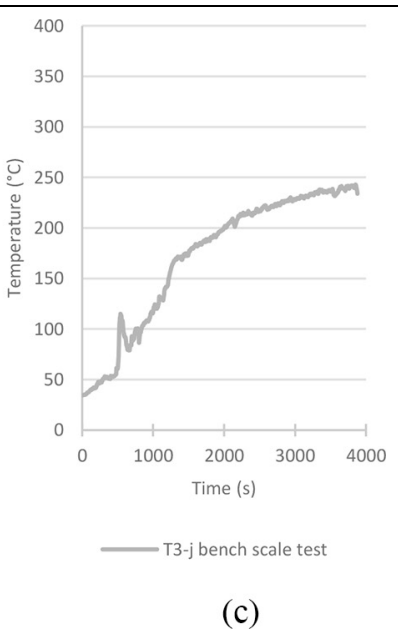

(c)

Figure 24. Time/temperature curves in the zones $A, B$, and $C$ for material with reference $C$ installed with a vertical junction on the bench-scale jetfire.

in zone A. When running the test, the going through the first protection layer occurred after $10 \mathrm{~min}$, but then there was no further visual change (Figure 25). After the test completion, it appeared that the seal was completely gone (Figure 26). In conclusion, the destruction makes a separation between zones A and B. Due to a combination of the seal decomposition and the direct impingement of the flame, temperatures are the highest in the B zone.

In this section, the effect of a vertical junction on the fire performance of the sample was investigated to mimic the assembly of panels evaluated at the real-scale jetfire. This setup allows to capture the thermal decomposition of the seal and its resulting influence on the temperature rise. The thermal decomposition of the silicone seal provides additional heat but it remains limited in time and the temperature remains lower than the criteria of $427^{\circ} \mathrm{C}$. 


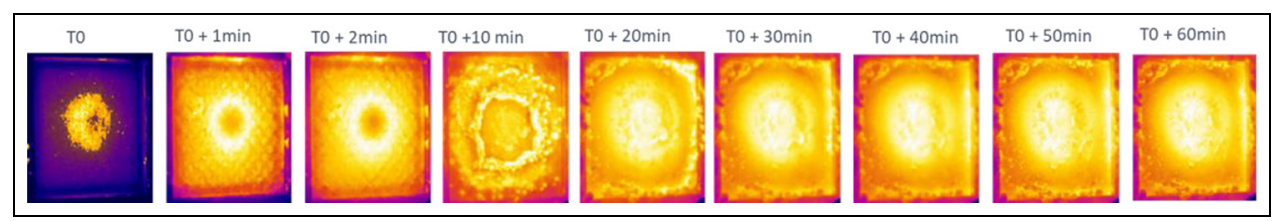

Figure 25. IR snapshots (filtered images eliminating the flame) of the fire behavior of material with reference $C$ installed with a vertical junction on the bench-scale jetfire.

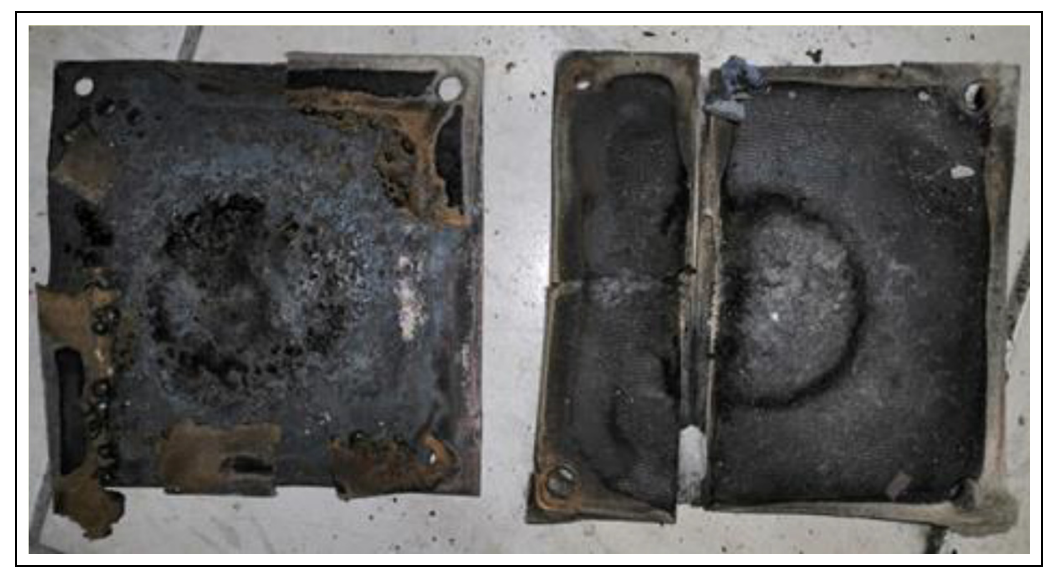

Figure 26. Sample (reference C) after testing at the bench-scale jetfire, the front face (left), and the back face showing the open junction (right).

\section{Conclusion}

In this article, a reduced-scale jetfire facility was developed (jetfire lab). The purpose was to assess a direct correlation between the large and the bench scale in terms of time-temperature curve. Based on results achieved at the real-scale jetfire, a specific design was drawn and validated at the bench scale. This design also permits to include a vertical junction on the sample to mimic the effects of an assembly, which is tested at large scale. With the developed setup, jetfire lab can capture the time-temperature curves of the large-scale jetfire and give prediction on the fire behavior of a sample at the large scale.

Jetfire lab offers, therefore, numerous opportunities to make fast screening and development of materials. It is instrumented with thermocouple and infrared (IR)/video cameras and can be used to make comprehensive studies and to evaluate new concepts of materials. Finally, the cost is strongly reduced compared to the large scale and is easy to use.

\section{Declaration of conflicting interests}

The author(s) declared no potential conflicts of interest with respect to the research, authorship, and/or publication of this article. 


\section{Funding}

The author(s) disclosed receipt of the following financial support for the research, authorship, and/or publication of this article: This work has received funding from the European Research Council (ERC) under the European Union's H2020 - the framework program for Research and Innovation (2014 2020) ERC Grant Advances Agreement No. 670747-ERC 2014 AdG/FireBar-Concept for FireBar Concept project.

\section{ORCID iD}

Serge Bourbigot (iD https://orcid.org/0000-0003-1536-2015

\section{References}

1. Chamberlain GA. Controlling hydrocarbon fires in offshore structures. In: Offshore technology conference, Houston, TX, 6-9 May 2002, pp. 1211-1218.[AQ: 8]

2. Mather P. Safety and fire protection: Fire protection $\xi$ passive. Int Hydrocarb 2002; 2002: 108.

3. ISO. Determination of the resistance to jet fires of passive fire protection materials - part 1: general requirements. Geneva: International Organization for Standardization (ISO), 2007, p. 40.

4. Bourbigot S, Bachelet P, Samyn F, et al. Intumescence as method for providing fire resistance to structural composites: application to poly(ethylene terephthalate) foam sandwich-structured composite. Compos Interface 2013; 20(4): 269-277.

5. Morys M, Illerhaus B, Sturm H, et al. Revealing the inner secrets of intumescence: advanced standard time temperature oven (STT Mufu + ) - $\mu$-computed tomography approach. Fire Mater 2017; 41(8): 927-939.

6. Maluk C, Bisby L, Krajcovic M, et al. A heat-transfer rate inducing system (H-TRIS) test method. Fire Safe J 2019; 105: 307-319.

7. Bourbigot S, Sarazin J, Bachelet $\mathrm{P}$, et al. Scale reduction: how to play with fire? In: 15th international conference and exhibition on fire and materials 2017, San Francisco, CA, 6-8 February 2017, pp. 137-144. London: Interscience Communications.

8. Bourbigot $\mathbf{S}$, Sarazin $\mathbf{J}$ and Bensabath T. Intumescent polypropylene in extreme fire conditions. Fire Safe J 2021; 120: 103082.

9. Drean V, Chiva R and Visse J. Resistance of passive protection materials to jet fires: numerical evaluation of thermal loads. Newsletter FABIG. Ascot: FABIG, 2020.

10. Ekoto IW, Houf WG, Ruggles AJ, et al. Large-scale hydrogen jet flame radiant fraction measurements and modeling. In: 9th international pipeline conference, IPC
2012, Calgary, AB, Canada, 24-28 September 2012, pp. 713-724. New York: ASME.

11. Wighus R. A test method for jet fire exposure. In: Partners $\mathrm{S}$ (ed.) 7th international symposium on loss prevention and safety promotion in the process industries. Taormina: SRP Partners, 1992, pp. 23-47.

12. Landucci G, Rossi F, Nicolella C, et al. Design and testing of innovative materials for passive fire protection. Fire Safe $J$ 2009; 44(8): 1103-1109.

13. Landucci G, Zanelli S, Paltrinieri N, et al. Analysis of the effectiveness of passive fire protection measures. In: 9 th international conference on chemical and process engineering, Icheap -9, Italian Association of Chemical Engineering - AIDIC, Rome, 10-13 May 2009, pp. 305310, https://www.aidic.it/icheap9/ CALL\%20FOR \%20PAPERS.pdf

14. Stolen R, Fjellgaard Mikalsen R, Glansberg K, et al. Heat flux in jet fires: unified method for measuring the heat flux levels of jet fires. In: Nordic fire and safety days (NFSD2018) conference Published by RISE Research Institutes of Sweden, Trondheim, 7-8 June 2018.

15. Sun L, Yan H, Liu S, et al. Load characteristics in process modules of offshore platforms under jet fire: the numerical study. J Loss Prev Process Ind 2017; 47: 29-40.

16. Roberts TA, Shirvill LC, Waterton K, et al. Fire resistance of passive fire protection coatings after long-term weathering. Process Saf Environ Prot 2010; 88(1): 1-19.

17. Adanménou R. Mesures àéchelle réduite de paramètres pertinents issus de scénarios feu, Science and Technologies. Lille: University of Lille, 2020.

18. Portevin A. La trempe des aciers et des alliages métalliques. Rev Met Paris 1922; 19(12): 717-740.

19. Kodur V, Dwaikat M and Fike R. High-temperature properties of steel for fire resistance modeling of structures. J Mater Civ Eng 2010; 22: 423-434.

\section{Author biographies}

[AQ: 7] 